\title{
MEETING ONLINE DENGAN MICROSOFT TEAMS
}

\author{
Muhammad Ullil Fahri \\ muhammad.fahri001@binus.ac.id \\ https://ullilfahri.skb.ovh/
}

Microsoft Teams adalah pengalaman yang benar-benar baru, yang menyatukan orangorang, percakapan, konten, serta alat yang diperlukan tim agar mereka dapat berkolaborasi dengan mudah guna meraih lebih banyak hal [1]. Dari pengertian diatas dapat dilihat microsoft teams didesain khusus untuk kolaborasi kerja bersama tim dengan menggunakan virtual. Pemanfaatan tim dalam ini tidak hanya diartikan untuk project besar saja. Pemanfaatan microsoft teams sekarang sudah sering digunakan dalam proses belajar secara virtual. Berikut adalah video singkat tentang microsoft teams [2] yang dapat anda akses pada tautan berikut https://bit.ly/3eKDebt . Berikut adalah fitur dari Microsoft teams [1] :

1. Obrolan untuk tim masa kini

Microsoft Teams menyediakan pengalaman percakapan modern untuk tim masa kini. Microsoft Teams mendukung tidak hanya obrolan berkesinambungan, tetapi juga berutas agar setiap orang tetap terlibat. Obrolan dapat dilakukan secara real time. Baik berupa pesan biasa hingga berupa video. Obrolan dapat dilakukan secara virtual room tanpa ada batasan ruang dan waktu.

2. Hub untuk kerja tim

Microsoft Teams menyatukan seluruh kualitas dan penawaran dari Office 365 guna menyediakan hub sebenarnya untuk kerja tim. Word, Excel, PowerPoint, SharePoint, OneNote, Planner, Power BI, dan Delve dapat ditemukan di Microsoft Teams, sehingga semua orang dapat langsung mengakses seluruh informasi dan alat yang diperlukan. Aplikasi yang sering digunakan di windows dapat langsung di fungsikan ke dalam aplikasi microsoft teams.

3. Dapat disesuaikan untuk setiap tim Microsoft Teams juga memiliki model Konektor yang sama seperti Exchange, yang menyediakan pemberitahuan serta pembaruan dari layanan pihak ketiga seperti Twitter atau GitHub. Kolaborasi dapat dilakukan secara lebih luas. Dalam pengembangan software development, microsoft team dapat membuat setiap programmer saling terhubung.

4. Kepercayaan tim keamanan

Microsoft Teams menyediakan kemampuan kepatuhan dan keamanan tingkat lanjut yang diharapkan pelanggan Office 365. Data dienkripsi saat transit dan saat disimpan di perangkat. Keamanan data anda di microsoft team terjamin. Semua data terenkripsi dengan sangat baik.

5. Microsoft Teams menggabungkan toolkit universal Office 365

Microsoft Teams menggabungkan portofolio terlengkap dari aplikasi dan layanan kerjasama untuk membantu mengatasi kebutuhan orang-orang dan organisasi yang beragam secara global. Banyak toolkit integrasi yang dapat digunakan seperti SharePoint.

Pada tulisan ini berfokus hanya pada satu fitur dari microsoft team yaitu fitur tentang pertemuan secara online. Microsoft Team menjadi salah satu opsi aplikasi video conference yang dapat mendukung kegiatan selama WFH ( Work From Home) . Aplikasi ini bisa di-download gratis dan tersedia untuk laptop atau komputer Mac, Windows 32 bit atau 
64 bit, hingga smartphone berbasis Android dan juga iPhone [3]. Dapat dilihat dari pendapat diatas microsoft team khusus meeting online mendukung banyak platform sehingga khusus untuk perangkat pendukung tidak terlalu masalah. Semenjak ada pandemi covid 19, penggunaan aplikasi rapat online menjadi meningkat, salah satu aplikasi yang dinilai sangat baik adalah meeting online dari microsoft team.

Berikut adalah cara membuat video conference dengan microsoft team [3] :

1. Download aplikasi Microsoft Teams di laptop, komputer, atau smartphone.

2. Jika sudah terinstal, masuk ke Microsoft Teams dengan mengetuk ikon aplikasi tersebut. Kemudian login dengan nama dan kata sandi Office 365.

3. Ketuk menu Teams yang ada di bagian bawah jendela aplikasi pada perangkat smartphone, dan di jajaran menu sebelah kiri pada perangkat komputer atau laptop.

4. Kemudian pilih tim dan saluran yang ingin kamu ajak untuk meeting. Kamu juga bisa membuat tim baru atau bergabung ke tim yang sudah ada.

Penulis memberikan tutorial khusus untuk client atau mahasiswa dari penggunaan microsoft team meeting online tanpa melakukan login.

\section{Menggunakan Komputer / Laptop / PC}

Silahkan hubungi guru atau dosen anda untuk meminta link Rapat online. Silahkan anda lakukan klik pada link tersebut . Anda akan diarahkan seperti pada gambar berikut :

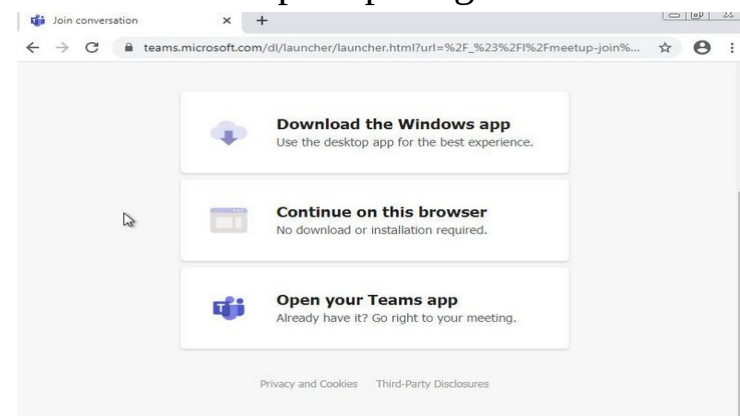

Gambar 1. Launching Rapat Online Microsoft teams
Pada gambar 1 merupakan tampilan awal ketika anda melakukan klik link join pada microsoft teams. Penulis menjelaskan fitur dari gambar 1 seperti berikut

1. Download The Windows APP artinya anda akan melakukan download aplikasi microsoft teams ke komputer.

2. Continue on this browser artinya melakukan pertemuan online dengan menggunakan web browser

3. Open Your Team app artinya membuka aplikasi microsoft team yang sudah terinstall.

Khusus mahasiswa agar proses cepat dalam join rapat online silahkan klik continue on this browser. Maka pertemuan online dilakukan menggunakan web browser. Akan tampil seperti gambar berikut :

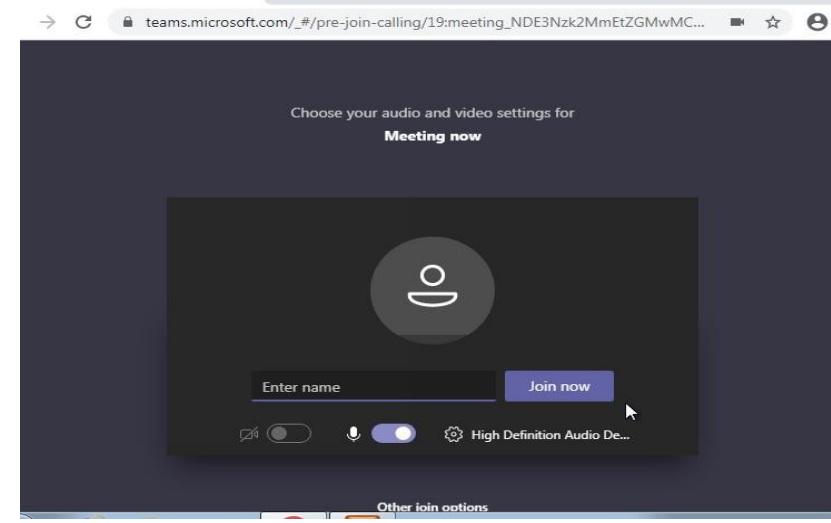

Gambar 2. Isi Identitas

Pada gambar 2 silahkan isi nama anda dengan jelas. Hal ini dikarenakan mempermudah host atau dosen membuat absensi ketika pelaksanaan rapat online atau pertemuan online.

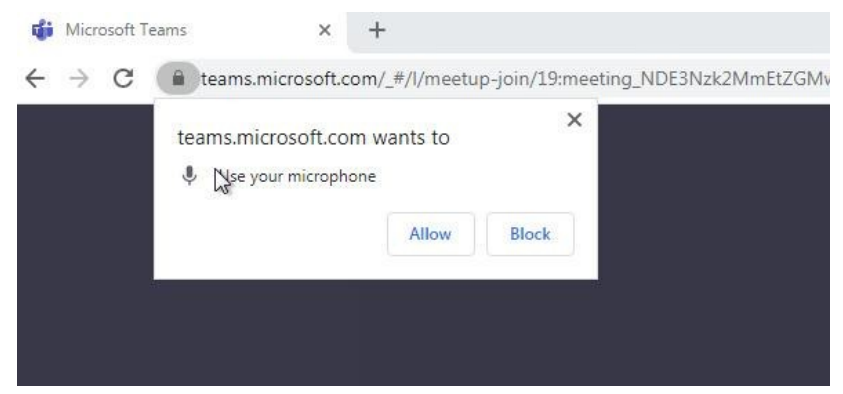

Gambar 3. Allow Mic dan Kamera 
Pada gambar 3 merupakan gambar dari permission / izin dari komputer. Silahkan anda pilih allow agar kamera dan suara anda bisa dilihat dan didengar oleh dosen atau peserta lainya.

2. Menggunakan Smartphone Android

Khusus penggunaan smartphone android, silahkan anda download pada tautan berikut https://bit.ly/38tDVVC

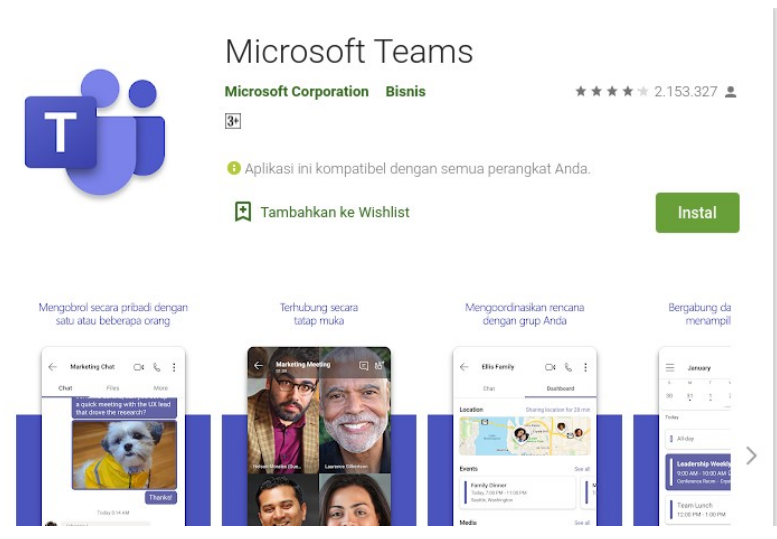

Gambar 4. Install Microsoft Team Android pada gambar 5 merupakan tampilan dari android setelah anda melakukan klik link. Silahkan tekan ikuti rapat. berikut :

Selanjutnya akan tampil seperti gambar

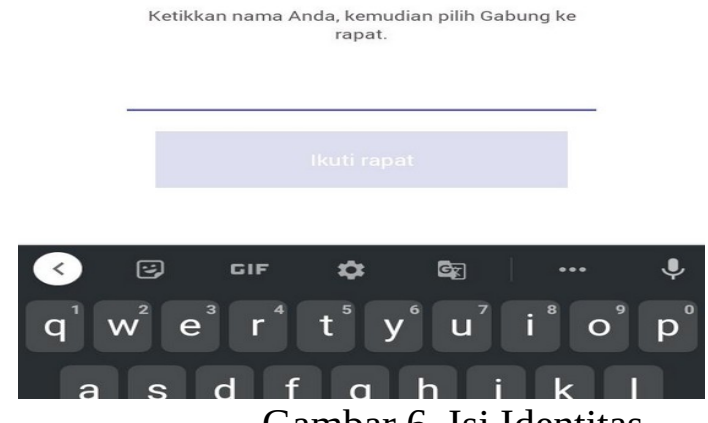

Gambar 6. Isi Identitas

Pada gambar 6 silahkan anda isikan nama anda dengan jelas.

Pada gambar 4 silahkan anda klik install. Setelah anda berhasil lakukan install silahkan anda meminta link join dari dosen atau guru anda. Setelah anda lakukan klik link join akan tampil seperti berikut :
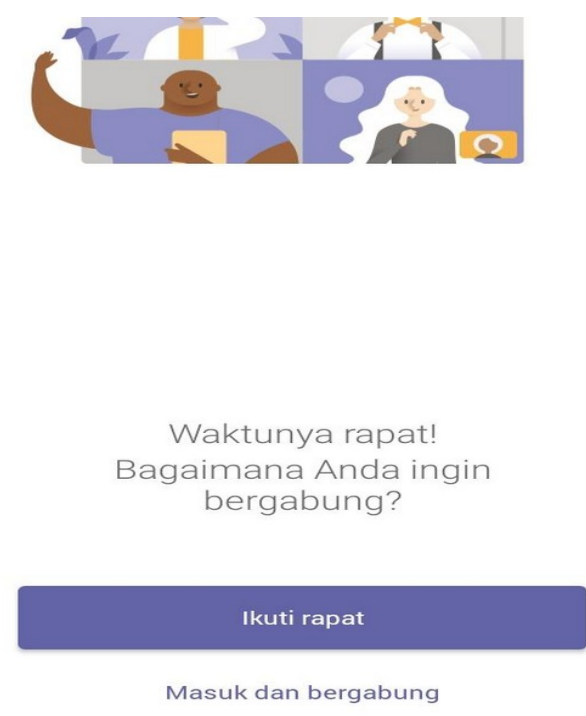

Gambar 5. Ikut Rapat 


\section{DAFTAR PUSTAKA}

[1] Microsoft, "Memperkenalkan Microsoft Teams, ruang kerja berbasis obrolan di Office 365," 2016. https://www.microsoft.com/id-id/microsoft-365/blog/2016/11/02/introducingmicrosoft-teams-the-chat-based-workspace-in-office-365/ (accessed Nov. 10, 2020).

[2] M. 365, “Introducing Microsoft Teams,” 2016. https://www.youtube.com/watch?v=nKUFMzZFF0 (accessed Nov. 10, 2020).

[3] A. R. Putri, “Cara Pakai Aplikasi Video Conference Microsoft Teams di Laptop dan HP,” 2020. https://kumparan.com/kumparantech/cara-pakai-aplikasi-video-conference-microsoft-teamsdi-laptop-dan-hp-1tGkrfjd9DS/full (accessed Nov. 10, 2020). 